Blackburn, TM; Lockwood, JL; Cassey, P; (2015) The influence of numbers on invasion success. Mol Ecol 10.1111/mec.13075.

\title{
Article
}

\section{The Influence of Numbers on Invasion Success}

Tim M. Blackburn ${ }^{1,2,3,4 *}$, Julie L. Lockwood ${ }^{5}$ and Phillip Cassey ${ }^{4}$

${ }^{1}$ Department of Genetics, Evolution and Environment, Centre for Biodiversity and Environment Research, University College London, Gower Street, London, WC1E 6BT, UK ${ }^{2}$ Institute of Zoology, ZSL, Regent's Park, London NW1 4RY, UK

${ }^{3}$ Distinguished Scientist Fellowship Program, King Saud University, P.O. Box 2455, Riyadh 1145, Saudi Arabia

${ }^{4}$ School of Biological Sciences, University of Adelaide, SA 5005, Australia

${ }^{5}$ Ecology, Evolution, and Natural Resources, Rutgers University, New Brunswick, NJ 08901 , USA

*Author for correspondence: t.blackburn@ucl.ac.uk

Running Head: Numbers and invasion success 


\section{Abstract}

The process by which a species becomes a biological invader, at a location where it does not naturally occur, can be divided into a series of sequential stages (transport, introduction, establishment and spread). A species' success at passing through each of these stages depends, in a large part, on the number of individuals available to assist making each transition. Here, we review the evidence that numbers determine success at each stage of the invasion process, and then discuss the likely mechanisms by which numbers affect success. We conclude that numbers of individuals affect transport and introduction by moderating the likelihood that abundant (and widespread) species are deliberately or accidentally translocated; affect establishment success by moderating the stochastic processes (demographic, environmental, genetic or Allee) to which small, introduced populations will be vulnerable; and affect invasive spread most likely because of persistent genetic effects determined by the numbers of individuals involved in the establishment phase. We finish by suggesting some further steps to advance our understanding of the influence of numbers on invasion success, particularly as they relate to the genetics of the process. 


\section{Introduction}

Hindsight is a wonderful thing. It is easy to look back with a critical eye on the best research produced by previous generations and feel good about oneself by observing only the shortcomings. A case in point is Baker \& Stebbins' (1965) edited Proceedings of the First International Union of Biological Sciences Symposia on General Biology. It is titled The Genetics of Colonizing Species, but the then state of the art means that it contains little focus on molecular genetics, and mainly focuses on ecological and quantitative genetics, and phenotypes assumed to have a genetic basis. It is also not always obvious what is meant by a "colonizing species", and indeed three different types of such species are identified (Mayr 1965). The bulk of the discussion in Baker \& Stebbins (1965) relates to species we would now term non-native or alien (i.e. species whose presence in a region is attributable to human actions, which have enabled them to overcome fundamental biogeographical boundaries; Richardson et al. 2011), and their volume is recognized as a classic text of invasion biology. Yet, to the eye of the modern invasion biologist there are some glaring omissions that serve to highlight how far the field has come over the last half century. Perhaps the most important of these is the lack of appreciation that invasion biology is primarily a succession of numbers games.

The process by which an alien species invades can be divided into a series of consecutive stages: transport (beyond native range limits), introduction (into the wild in a new environment), establishment (of a viable alien population), and finally (invasive) spread (Blackburn et al. 2011). Recognition that the number of individuals matters greatly to this process arose from developments in conservation biology, where, it had become apparent that the persistence of small populations depends fundamentally on population size (Caughley 1994). Initially, the importance of numbers was largely considered in terms of establishment success, but it was quickly realized that the number of individuals matter at all invasion stages. Thus, abundant native species are more likely to be entrained in a transportation mechanism and later released into a new location (Blackburn \& Duncan 2001). Species more abundant in captivity are also more likely to be released (Cassey et al. 2004a; Chang et al. 2009). Introduced populations are more likely to establish if more individuals are released (higher 'propagule pressure', which is the sum over all release events of the number of individuals released to form a population, sometimes also termed 'introduction effort': Cassey et al. 2004b, 2005; Lockwood et al. 2005; Hayes \& Barry 2008; Blackburn et al. 2009; Simberloff 2009), and populations introduced with higher propagule pressure, or that produce more offspring in the new environment, are more likely to spread (Duncan et al. 1999, 2001; Caswell et al. 2003; Signorile et al. 2014). Several chapters in Baker \& Stebbins mention numbers in the context of colonization by alien species, but 
primarily as a consequence of invasion, not as a cause (e.g. Birch 1965; Fenner 1965; Fraser 1965; Harper 1965; Sakai 1965). None presage the prominence this issue has now achieved. Today, the key questions are not about whether numbers influence invasion success, but how.

The invasion stage that has received most attention in terms of the influence of numbers is establishment. Most alien populations start out at very small numbers (Blackburn et al. 2009, figure 3.1). Population dynamic theory and conservation practice both demonstrate that small populations are more likely to go extinct, on average, than larger populations (see any ecology or conservation text book). We would expect extinction risk to vary with population size for alien as well as for native populations, and so it is no surprise to find that propagule pressure is generally strongly positively correlated with establishment success (Lockwood et al. 2005; Colautti et al. 2006; Hayes \& Barry 2008; Blackburn et al. 2009; Simberloff 2009). Nevertheless, small populations are vulnerable to a variety of processes, including demographic stochasticity, environmental heterogeneity, Allee effects, and genetic effects (Morris \& Doak 2002; Cassey et al. 2014). We might expect the precise mechanisms underlying the relationship between numbers of individual and persistence to differ for native and alien populations. For example, the importance of environmental heterogeneity or Allee effects may differ for species new to a location versus species with a long evolutionary history in that environment. The role of genetic effects may also differ for populations structured by natural versus anthropogenic processes. To date, few studies have explored the influence of propagule pressure on alien population establishment in ways that allow us to discriminate between the actions of these different processes.

Here, we review evidence that helps us to understand how the broad positive relationship between numbers and invasion success might be driven, considering all stages in the invasion process. In the spirit of Baker \& Stebbins (1965), we highlight how numbers might interact with genetic effects where possible. However, as Ernst Mayr noted in his concluding remarks to the Proceedings, "I am sure every ecologist here realises that he (sic) really ought to know more about genetics", and that very much applies to the three of us.

\section{Numbers, Transport and Release}

The early stages of the invasion pathway concern which species are transported beyond the limits of their native geographic ranges, and which of these species are subsequently liberated into new environments. In many cases, the first evidence that species have been transported and released outside their native ranges comes when free-living individuals are observed within a new environment. Hence, most studies of these early stages of invasion 
concatenate transport and release. A basic dichotomy in classification at these early invasion stages is whether individuals are moved intentionally or unintentionally by humans (Lockwood et al. 2013). Either way, the number of individuals in the native population matters.

Examples of accidental transport and release include individuals caught up in the ballast (soil or water) of ships, within the packing material used for dry cargo, or as hitch-hikers living beside or within a purposefully traded species (Mack 2003; Hulme et al. 2008; Hulme 2009). Under these circumstances, individuals of alien species find themselves entrained in a transport vector essentially at random. Species more prevalent in their native environment are by chance alone more likely to be unintentionally transported (Hulme 2009), and more likely to be present in those samples in higher numbers (Wonham et al. 2001). Species that have adapted to human-altered habitats may be more likely to be transported by accident than species that shun anthropogenic environments (Hufbauer et al. 2012), but we would still expect accidental transport to concern more abundant species in these environments. The same processes apply also to intraspecific variation, such that higher frequency genotypes (and phenotypes) are more likely to be captured for transportation and release (Nei et al. 1975). In sum, accidental transport and introduction filters out rarity. Random sampling processes also result in larger numbers of individuals per species being introduced as the size of the sample increases (Lockwood et al. 2009), which has further consequences for the probability that an alien species will establish a viable population once released (see below).

The same is true for many species deliberately transported and released. Species may be intentionally moved for a variety of reasons, including as game animals, ornamental plants or animals, as biocontrol agents, or for the purposes of conservation (Lockwood et al. 2013). Identity will clearly matter in such cases - not all plants are equally desirable as ornamentals, for example (Pysek et al. 2003) - but the availability of species for capture and transport typically matters too. Thus, birds transported from the UK to New Zealand tended to be species that are abundant and resident in the UK (Blackburn \& Duncan 2001). Similarly, parrots that are transported outside their native ranges tend to be widespread species, and widespread and abundant parrot species are more likely to be released or escape into novel regions (Cassey et al. 2004a). While non-randomness in the taxonomic composition of species has revealed that certain types were preferentially moved (e.g. wildfowl, gamebirds; Blackburn \& Duncan 2001), the species introduced were nevertheless those that were the most readily available and easily obtained (Figure 1). Abundant species tend also to be widespread (Gaston \& Blackburn 2000) and so likely to be available for collection at a wide range of locations. For any given species, higher frequency genotypes 
and phenotypes are again more likely to be moved. Thus, with the acknowledgement that some deliberately transported species are rare in their native range, we should expect commonness to also be favoured in the deliberate movements of species.

These transport filters have consequences for subsequent invasion stages, as they determine which species become exposed to novel environments (Cassey et al. 2004a). Common, widespread species are common and widespread for a reason. While it is still not obvious if we can identify the actual underlying processes with much confidence, the breadth or typicality of species' environmental requirements or tolerances seem likely to be important determinants of establishment success and subsequent invasive spread (Gaston 1994, 2003; Gaston \& Blackburn 2000). Alternatively, species that have adapted to human-altered habitats may be more likely to be both transported and able to exploit conditions they find on release (into other human-altered habitats; Hufbauer et al. 2012). Either way, the early stages of the invasion process may be selecting for species that are pre-adapted to cope with conditions they will encounter in the new location (Chapple et al. 2012). This may in part explain why establishment success is surprisingly high in at least some groups of alien species (e.g. Williamson 1996; Gaston et al. 2003; Jeschke 2008). Random sampling processes also result in larger numbers of individuals per species being introduced as the size of the sample increases, which has further consequences for the probability that an alien species will establish a viable population once released (Lockwood et al. 2009).

\section{Numbers and Establishment Success}

Once an alien species is released into a novel environment, the individuals must found a self-sustaining population in order to be considered 'established' (Lockwood et al. 2013). The probability that this will happen is higher for alien populations that are founded by relatively large numbers of individuals. If these individuals are released over more than one location, or at more than one time, the probability of establishment may also be higher. These relationships result because the perils of small population size tend to ensure that populations with few founders will eventually become extinct (Lockwood et al. 2005; Hayes \& Barry 2008; Blackburn et al. 2009; Simberloff 2009). Demographic stochasticity, environmental stochasticity, Allee effects, and genetic effects are all likely to play a role in increasing the chances that a small population will fail to establish. However, the actual contribution of each of these processes in the context of invasions is as yet unresolved. We are nevertheless gaining insights into these relationships from the increasing application of theoretical models of invasion dynamics to empirical data. These models show that different processes are expected to produce different relationships between propagule pressure and establishment success. 
Duncan et al. (2014) derived the expected relationship between establishment probability and the number of individuals released for populations under the influence of demographic stochasticity, Allee effects, and among-population environmental heterogeneity in establishment conditions. They assumed that founding populations initially were composed of far fewer individuals than the location's carrying capacity, and noted that a population will establish if at least one individual leaves a surviving lineage (Caswell 2001; Fox 2005). Under demographic stochasticity alone, the probability of establishment, $P_{\text {est, }}$, for a newly introduced population of size $N_{0}$ is:

$$
P_{\mathrm{Est}}=1-(1-p)^{N_{0}}
$$

where $p$ is the probability that each individual leaves a surviving lineage. Demographic stochasticity affects all populations, and so Duncan et al. (2014) used equation 1 as the base to which to add additional effects. They incorporated Allee effects by adding a term that models changes in the birth rate at different population sizes: a disproportionate decline in birth rate at low population sizes is expected under Allee effects. They incorporated amongpopulation environmental heterogeneity by modeling variation in the probability of individual establishment, $p$, across different locations as drawn from a beta distribution.

Duncan et al. (2014) tested the fit of these different models to data for 55 experimental releases of the alien psyllid Arytainilla spartiophila to New Zealand for the purposes of biocontrol (Memmott et al. 2005). The data were best fit by the model of establishment success as a function of demographic stochasticity plus Allee effects, although the model of demographic stochasticity plus among-population heterogeneity also fitted the data reasonably well. Establishment success was relatively poorly predicted by demographic stochasticity alone. However, the best fitting model revealed that establishment probability per individual was actually proportionately lower at large population sizes, not at small population sizes as expected under a classic Allee effect. Duncan et al. (2014) found similar effects for global data on the outcome of bird species introductions (using data in Sol et al. 2012), with disproportionately lower per individual success rates when large numbers of birds were released.

These models suggest that variation in establishment success can broadly be explained by two processes. First, the decline in success at small propagule pressures (the left hand side of Figure 2) is consistent with the effects of demographic stochasticity. Second, the disproportionate decline in success (per individual released) for larger releases suggests that success here is being driven by factors largely unrelated to the initial size of a population. This would be expected if populations are being introduced to areas that are 
unsuitable for their establishment, regardless of how many individuals are involved. Interestingly, Memmott et al.'s (2005) data showed substantial variation in the probability that each individual leaves a surviving lineage ( $p$; see inset panel in Figure 2), with many sites having a very low probability of establishment. This observation implies that even large populations of psyllids were destined to go extinct at some of the release sites. Indeed Memmott et al. (2005) noted that while small introduced psyllid populations tended to go extinct very quickly (consistent with demographic stochasticity), surviving populations were then prone to extinction due to site destruction, which affected populations regardless of their size.

Duncan et al. (2014) explored establishment probability as a function of the number of individuals released, but ignored the fact that this number can be arrived at in a number of different ways. In particular, $N$ total individuals may derive from one large or several smaller release events (Lockwood et al. 2005). Different release configurations will clearly influence the relative impacts of demographic stochasticity versus Allee effects (and environmental suitability), but the precise outcome is likely to be influenced by how these effects are manifested. Hopper \& Roush (1993) suggested that multiple, small releases may be more likely to establish than a single large one under environmental heterogeneity, because increasing the number of releases increases the probability that one of those will coincide temporally or spatially with favourable environmental conditions. This argument has subsequently been confirmed by a variety of models (e.g. Haccou \& Iwasa 1995; Grevstad 1999; Haccou \& Vatutin 2003). Conversely, simulations by Cassey et al. (2014) found that the probability of establishment was negatively correlated with the number of separate release events, and the time between them, even under conditions of extreme (inter-annual) environmental variability. They attributed their results to the fact that a single, large release will grow more quickly in population size, and hence is more capable of riding out harsh environmental conditions, while less likely to be reduced to a level where demographic and typical Allee effects are relevant. However, Cassey et al. (2014) modeled releases distributed in time, but not in space. Multiple releases to different locations may enhance the probability that some of those released individuals encounter a favourable environment simply because these conditions are more variable across space than through time at a single location (c.f. Haccou \& Iwasa 1995; Haccou \& Vatutin 2003; Duncan et al. 2014).

The number of individuals released, and how they are released, are also likely to determine the impacts of genetic stochasticity in alien populations. Smaller releases are likely to have lower genetic diversity, and higher likelihoods of population bottlenecks, genetic drift, and inbreeding, all of which can cause declines in mean fitness (Figure 3; Frankham et al. 2004). These founder effects will be exacerbated if the population remains small for a number of 
generations (Nei et al. 1975). All of these effects may decrease the probability that an alien species will establish a self-sustaining population.

Releasing a given number of individuals in several small releases distributed across space (or time) may exacerbate these problems by forcing the population through a series of smaller bottlenecks. Alternatively, it has been suggested that multiple releases may promote establishment by providing a 'genetic rescue effect' (sensu Carlson et al. 2014) by supplementing genetic diversity, especially in cases where supplementary individuals come from different source populations (Sakai et al. 2001; Brook 2004). While alien populations are expected to sample only a proportion of the genetic variation present in their native range (see e.g. Dlugosch \& Parker 2008), there are prominent examples where local alien populations are genetically more diverse than local source populations (e.g. Kolbe et al. 2004). Individuals deriving from diverse donor locations may not only increase genetic diversity and reduce the likelihood of bottlenecks, but may also trigger novel outcrossing events that can increase the adaptive potential of an introduction (Novak \& Mack 2005), or import novel genetic variation that allows evolutionary rescue (see below). Conversely, they may also lead to outbreeding depression.

Dlugosch \& Parker (2008) reviewed studies of genetic variation in introduced versus native ranges, finding data for 80 alien species from a range of taxa. While they found some examples where genetic diversity was higher in the alien range, in most populations it was lower. The average loss of diversity was estimated at between 5.8 and $32.7 \%$, depending on the molecular marker. However, the extent of this loss was smaller for populations that had resulted from multiple introduction events. These patterns would be expected under a genetic rescue effect, but could also be explained if multiple introductions tended to have higher propagule pressures. This is certainly the case for bird introductions to New Zealand, where number of individuals of a species released at a location is highly positively correlated with the number of releases $(r=0.73, N=92, P<0.001$; from data used by Blackburn et al. 2013). Dlugosch \& Parker (2008) do not control for this effect, but a subsequent metaanalysis of animal and plant introductions showed that genetic diversity tends to be higher for alien populations deriving from multiple introductions, controlling for the number of individuals introduced (Uller \& Leimu 2011). Nevertheless, these analyses do not inform about the influence of genetic effects on establishment success, as they do not include genetic data for failed introductions (these are considerably more difficult to come by). A field experiment by Ahlroth et al. (2003) does suggest that genetic composition may be important: they found that the likelihood of successful colonization increased with propagule pressure for introduced waterstriders populations, but that colonization success was higher, for a given propagule pressure, when founders came from two versus one source populations. 
Nevertheless, the maximum number of founders introduced by Ahlroth et al. (2003) was only 16. Even releases involving few individuals can sample much native genetic diversity (Novak \& Mack 2005; see also Roman \& Darling 2007), suggesting that genetic effects may be relevant only to the smallest releases.

The population model of establishment success explored by Cassey et al. (2014) supports this interpretation. They included genetic effects by modeling inbreeding depression, and identified four factors that were influential in determining establishment in their simulations: net reproductive rate per female, the number of individuals released, the influence of extreme environmental events, and the strength of inbreeding effects. The genetic effects were the smallest of the four. Inbreeding had negligible effects on establishment probability in cases where success or failure is more or less guaranteed on the basis of other modeled parameters, but could tip the balance towards failure for populations with intermediate chances of establishment. Overall, their models found that a single release was always more successful than multiple releases, all else being equal, even under conditions of extreme environmental variability. One large release grew more quickly, was less likely to be reduced to a population size where demographic, genetic, and Allee effects come into play, and could exploit favourable conditions when they occurred. All that spreading out the release of more individuals did, in terms of establishment success, was to delay their reproductive contribution to future generations (Cassey et al. 2014). However, their model did not incorporate negative density dependence, and so it is possible that multiple releases may matter more for populations that are highly constrained in size.

Alien populations are not fixed entities, but can evolve to meet challenges of novel environments to which they are not pre-adapted (Sakai et al. 2001). Adaptation that occurs rapidly enough that a population recovers from environmentally induced demographic effects that otherwise would have caused extinction is termed 'evolutionary rescue' (Gomulkiewicz \& Holt 1995; Gonzalez et al. 2013; Carlson et al. 2014). The recent growth of interest in evolutionary rescue is largely driven by attempts to understand the likely responses of species to rapid, anthropogenic environmental change (Gonzalez et al. 2013), but it is clearly also relevant to biological invasions (e.g. Holt et al. 2005). The likelihood that evolutionary rescue occurs will also be influenced by propagule pressure, because the size of a population is generally positively related to the rate at which it can adapt, and to the maximal rate of environmental change to which it can adapt (Lanfear et al. 2014). Larger populations may also take more time to decline to the size at which extinction due to stochastic processes is likely, although this will depend also on the degree of maladaptation (Holt et al. 2005), and hence the rate of population decline (Carlson et al. 2014). Moreover, the likelihood of evolutionary rescue is higher for populations with greater standing genetic 
variation available for selection to act upon (Bell 2013; Carlson et al. 2014), which also should be positively related to propagule pressure.

Evolutionary rescue may be influenced by how individuals are released. Multiple releases may promote evolutionary rescue if the additional propagules import novel genetic material or increase opportunities for mutations (Carlson et al. 2014). Once again, however, it is not obvious that these benefits would be greater than if the population derived from a single release of the same total number of individuals. Conversely, multiple releases may hamper evolutionary rescue if the immigrants bring maladaptive genes into the population (e.g. Schiffers et al. 2013), which could eliminate fitness gains made from adaptation in the original release. This suggests that, in some cases, multiple releases may actually reduce the likelihood of establishment by an alien population, although we are not aware of any examples of this.

Models and analyses of historical data on establishment success have been informative about the potential and actual influence of numbers introduced, but we are now at a point where the most useful development would be more experimental tests of the processes concerned. There is a small but growing number of such studies (Grevstad 1999; Ahlroth et al. 2003; Drake et al. 2005; Memmott et al. 2005; Fauverge et al. 2007; Bailey et al. 2009; Bell \& Gonzalez 2009; Gertzen et al. 2011; Hufbauer et al. 2013; Szucs et al. 2014). Experiments that manipulated the genetic composition of individuals introduced to locations (e.g. microcosms, enclosures) in different numbers and multiples of events could be particularly rewarding in distinguishing the influence of genetic, demographic and Allee effects. Recent studies by Hufbauer et al. (2013) and Szucs et al. (2014) that manipulated the numbers and genetic composition of insects introduced to experimental arenas are an excellent first step. For example, Szucs et al. (2014) demonstrated that establishment success in populations of Tribolium beetles depended on founder size but not on their genetic provenance (inbred to outbred), although subsequent population growth was depressed at low founder sizes for inbred lines.

\section{Numbers and alien species spread}

The influence of numbers on the process of invasion continues beyond the establishment phase to influence how far alien species spread across the new environment. Here, numbers affect spread (invasiveness) in two broad ways.

First, populations that produce more offspring in the new environment are more likely to spread more widely across it (Caswell et al. 2003). For example, successful plant invaders 
tend to be more fecund compared to their native congeners or related taxa, and to alien congeners with different degrees of invasiveness (Pyšek \& Richardson 2008). Bird species with life history traits associated with higher fecundity (and higher rates of population growth) have larger alien geographic range sizes in both New Zealand (Duncan et al. 1999) and Australia (Duncan et al. 2001). This relationship may arise if the process of spread in a new environment is functionally equivalent to a sequence of establishment events (Blackburn et al. 2011). Under this analogy, an alien species that has established a sustainable population at a "beach-head" in a new environment then spreads by establishing further populations at new locations, at each of which the same challenges that faced the original introduction are overcome. Just as the number of individuals in the initial introduction is of fundamental importance to that first establishment, so too is the number of individuals that reach subsequent locations a key determinant of the likelihood of establishes there. All else being equal, increasing local abundance boosts the number of propagules available for dispersal to new, unoccupied locations. If higher fecundity increases a population's local abundance, then a relationship between fecundity and spread would be expected.

Second, populations introduced to the new environment in larger numbers are not just more likely to establish a viable population there, but are also more likely to spread more widely across it (e.g. Duncan et al. 1999, 2001). Thus, the influence of propagule pressure appears to extend beyond the establishment phase, also to determine alien range size. Propagule pressure is argued to affect establishment success because it helps populations to overcome the consequences of Allee effects, and of demographic, environmental and genetic stochasticity (Figure 3, see above). Population and conservation biology tell us that the first three of these processes quickly lose their threat to a population's persistence as it grows away from small numbers. The residual influence of propagule pressure therefore seems most likely to act through the continued impacts of genetic effects.

Alien species typically pass through a small population bottleneck on the pathway to establishment, and the concomitant declines in genetic diversity and increases in the likelihood of inbreeding can effect fitness over extended time frames (Figure 3). For example, a review of genetic variation in established alien bird species found that more severe bottlenecks reduced genetic variability in the resulting populations, relative to the native range (Merilä et al 1996). Briskie \& Mackintosh (2004) used data on the breeding success of alien bird species established in New Zealand to demonstrate that rates of hatching failure were a negative function of the number of individuals introduced. Their data suggest that increases in failure rates are mainly expressed in populations for which fewer than 100 individuals were introduced (Figure 4). Given that the species analysed by Briskie \& Mackintosh (2004) were introduced in the middle of the nineteenth century, their data 
suggest that the fitness consequences of passing through a population bottleneck are still being expressed more than a century after the bottleneck occurred. An alternative outcome is that prolonged inbreeding will allow harmful genetic mutations to be expressed, and that these mutations will then be 'purged' from the population via selection (Frankham et al. 2004). If this situation pertains in alien invasions, we should expect that some alien populations established with few individuals, and whose populations remained low but persistent for long periods, will eventually begin to express higher fitness. For example, Facon et al. (2011) showed that inbred individuals of the ladybird Harmonia axyridis from the native range showed greater inbreeding depression than individuals from alien populations, suggesting that recessive deleterious mutations had been purged from the latter.

The fitness consequences of bottlenecks for alien species may affect the dynamics of their populations. For example, the experimental work of Szucs et al. (2014) showed that populations of Tribolium that establish from low propagule pressures grow more slowly if those founders are inbred, while dispersal rates in these populations increase with genetic diversity. Their results imply that population growth and spread following establishment can both be driven by genetic processes. Similarly, Signorile et al. (2014) studied alien grey squirrel (Sciurus carolinensis) populations at four locations in Europe. They found that genetic variation across these populations increased with founder population size, and that there was a positive relationship between founder population size and the rate of population spread. A common feature of the population growth curves of alien populations is a lag phase, defined as a period of slow population growth followed by a marked increase in the rate of growth (Shigesada \& Kawasaki 1997; Williamson et al. 2005; Aikio et al. 2010; Aagaard \& Lockwood 2014). The lag phase may be a simple consequence of the form of population growth curves, but may also reflect the time taken for the population to produce the necessary adaptations to allow spread (Crooks \& Soulé 1999). If so, losses of genetic variation that result from low propagule pressure and subsequent slow population growth may promote longer lag phases by reducing the genetic diversity available for selection to act upon.

The sampling effect of bottlenecks may also reduce the likelihood that individuals with appropriate adaptations to allow spread are introduced to a new location (McCauley 1991) (Figure 4). For example, Zenni et al. (2014) showed that range expansions by alien Pinus taeda resulted from an interaction between the genetic provenance of the introduced individuals and the climate in the alien range. These invasions are led by plants with a genotype that conveyed higher fitness in the alien range, which suggests that the invasions would have at best proceeded more slowly had this genotype not been initially introduced. Such effects may also influence the extent of the alien range size. 
The impacts of introduction history can have long-term effects through genetic stochasticity, but as with the effects of demographic and environmental stochasticity, these impacts are likely to decrease as an alien population grows and spreads. Selection may, depending on the precise conditions, purge exposed deleterious recessive alleles, weakening inbreeding depression over time (Frankham et al. 2004). Dlugosch \& Parker (2008) found some evidence that the proportional change in genetic diversity in alien relative to native populations shows a U-shaped relationship to the length of time that an alien species has been established, at least for species established from multiple introduction events (but see Uller \& Leimu 2011). Allelic richness decreased with time across populations up to around $80-100$ years after first introduction, but then started to increase again. Dlugosch \& Parker (2008) argued that drift and strong selection were likely to have caused a loss of withinpopulation genetic diversity in the initial phase of establishment, for all initially established alien populations, given their associated slow population growth. However, as these alien populations increased in numbers and became more connected through dispersal (integrating more across multiple populations at multiple introduction sites), genetic diversity would begin to increase again (Figure 5). This relatively higher genetic diversity can then be preserved during population expansion (when populations might be expected to go through a series of bottlenecks with each new colonization event, or suffer from gene surfing by deleterious alleles; Edmonds et al. 2003), probably as a result of frequent long-distance dispersal events (e.g. Berthouly-Salazaar et al. 2013).

Based on the evidence we present above, we suggest that the degree to which alien species will show a U-shaped pattern in diversity is dependent on at least two factors; (1) numbers of individuals initially released, and (2) the degree of genetic structure in the native range and how the transport process 'samples' this variation (Figure 5). These two factors essentially determine the 'down' and 'up' of the U-shape, respectively. All available evidence suggests that the loss of genetic variation at the time of founding is dependent on propagule pressure. This manifests through founder effects and bottlenecks, but can also result from the synergistic effect of these factors dictating long periods of slow population growth leading to drift. Thus, the smaller the propagule pressure for any of the initially established populations of an alien species, the steeper and deeper the drop into the bottom of the U-shape. Once these independently established populations begin to exchange individuals, they establish gene flow, effectively homogenizing any existing differences in genetic variation across populations. If the initial populations are effectively drawn from a single panmictic native source, the rise in diversity in the alien range from gene flow will be minor; gene flow in this case will only be overcoming the effects of randomly sampling alleles from a single large population. However, if the initial populations are founded by individuals taken from across 
the native range, and there is a high degree of geographical genetic structure in this range, the rise up the U-shape will be steeper. In this case, gene flow effectively represents admixture whereby alleles from divergent sources are intermixing in a single population.

\section{Conclusions}

Looking through the older literature on invasions, it is not that surprising that none of the contributors to Baker \& Stebbins (1965), or any of the other early works on invasion biology (e.g. Elton 1958, Drake et al. 1989), recognized the importance of numbers of individuals on the dynamics of biological invasions. The arguments we proffer here result from an intense interest in small population dynamics within conservation biology and the ability to track the loss (and gain) of genetic diversity that accompanied transformative genetic technologies. Each of these lines of inquiry really only produced their insights from the late 1980s and early 1990s. What they bring to invasion biology is the fundamental insight that numbers matter at all stages of the invasion process. We have reviewed evidence for these effects above, but we also hopefully have highlighted gaps in our understanding of them, especially as they relate to the influence of genetic diversity. Below we summarize what we see are the three next steps to pushing our understanding past its current position, and associated debates.

First, empirical studies clearly show the profound influence that the transportation and release stage of invasions have on the genetic composition of alien species, and that the number of individuals transported strongly mediates these effects. However such studies are few in number, and their insights have not apparently penetrated a good portion of the invasion literature as yet. For example, Dlugosch and Parker (2008) were able to source information on differences in genetic diversity between 80 alien and native populations. They found some consistent patterns, but there was also much variation present. Knowledge of the transport dynamics behind each of these introduction events, including the number of individuals released across spatial and temporal scales, could explain much of this variation. As yet, there have been very few attempts to make these connections. Given the potential for knock-on effects of low genetic diversity across all invasion stages, we suggest that these connections will prove insightful relative to our understanding of invasion dynamics.

Second, the general influence of propagule pressure on establishment success is well supported across species and ecosystems (Lockwood et al. 2005, Colautti et al. 2006, Hayes \& Barry 2008, Simberloff 2009). The more individuals released, the more likely an incipient alien population is to persist. The mechanisms behind this relationship are easy to speculate upon, and we detail them above, but they have only recently been actively under 
investigation. For example, recent modeling and empirical evidence strongly suggests that the relationship between numbers released and establishment is an increasing but asymptotic function (see e.g. Figure 2). One under-explored possibility is that variation is influenced by genetic variability on population growth, either manifest as inbreeding depression (very low numbers) or admixture (very high numbers). The existence and location of these effects would be likely to vary across species, for example according to their life history traits. There is a clear need to explore genetic and other mechanisms behind the role of numbers released on establishment success, including the synergistic interactions of these mechanisms with one another.

Finally, the link between propagule pressure and subsequent invasive spread sits squarely within the realm of genetics. There is some evidence that low genetic variability within an alien population can limit its potential to adapt to novel conditions in the new range, cause lasting negative effects on survival and reproduction, or trigger a behavioral change that is maladaptive in the new range. There is also evidence that some invasive populations have benefited from the purging of deleterious alleles as a consequence of passing through a bottleneck at introduction, while some invasive populations have higher genetic diversity than in the native range as a result of admixture and hybridization. There is considerable room for exploration in this area, and we suggest that future investigations explicitly consider the link between 'standing' genetic variation in an alien species and the number of individuals (and the source of these individuals) in producing this variation. Making these connections will provide crucial insight into our basic understanding of the role of genetic variation in species' range sizes, but more practically into our ability to predict which newly introduced alien species may go on to become invasive.

\section{Acknowledgements}

We thank Katrina Dlugosch, Richard Duncan, Ruth Hufbauer and Marianna Szucs for helpful discussions, and for drawing our attention to key literature. This study was supported by the King Saud University Distinguished Scientist Fellowship Program and John Wiley \& Sons Inc. (TMB), and by an ARC Discovery Grant (DP140102319) and Future Fellowship (FT0991420) to PC. 


\section{References}

Aagaard K, Lockwood JL (2014) Exotic birds show lags in population growth. Diversity and Distributions, 20, 547-554.

Ahlroth P, Alatalo RV, Holopainen A, Kumpulainen T, Suhonen, J (2003) Founder population size and number of source populations enhance colonization success in waterstriders. Oecologia ,137, 617-620.

Aikio S, Duncan RP, Hulme PE (2010) Lag-phases in alien plant invasions: separating the facts from the artefacts. Oikos, 119, 370-378.

Baker HG, Stebbins GL (1965) The Genetics of Colonizing Species. Academic Press, New York, NY.

Bailey SA, Vélez-Espino LA, Johannsson OE, Koops MA, Wiley CJ (2009) Estimating establishment probabilities of Cladocera introduced at low density: an evaluation of the proposed ballast water discharge standards. Canadian Journal of Fisheries and Aquatic Sciences, 66, 261-276.

Bell G (2013) Evolutionary rescue and the limits of adaptation. Philosophical transactions of the Royal Society of London. Series B, Biological sciences, 368, 20120080.

Bell G, Gonzalez A (2009) Evolutionary rescue can prevent extinction following environmental change. Ecology letters, 12, 942-8.

Berthouly-Salazar C, Hui C, Blackburn TM, Gaboriaud C, van Rensburg BJ, et al. (2013) Long distance dispersal maximizes evolutionary potential during rapid geographic range expansion. Molecular Ecology, 22, 5793-5804.

Birch LC (1965) Evolutionary opportunity for insects and mammals in Australia. In: The Genetics of Colonizing Species (eds Baker HG, Stebbins GL), pp. 197-211. Academic Press, New York, NY.

Blackburn TM, Duncan RP (2001) Establishment patterns of exotic birds are constrained by non-random patterns in introduction. Journal of Biogeography, 28, 927-939.

Blackburn TM, Lockwood JL, Cassey P (2009) Avian Invasions. The Ecology and Evolution of Exotic Birds. Oxford University Press, Oxford.

Blackburn TM, Pyšek P, Bacher S, Carlton JT, Duncan RP, et al. (2011) A proposed unified framework for biological invasions. Trends in Ecology \& Evolution, 26, 333-339.

Blackburn TM, Prowse TAA, Lockwood JL, Cassey P (2013) Propagule pressure as a driver of establishment success in deliberately introduced exotic species: fact or artefact? Biological Invasions, 15, 1459-1469.

Briskie JV, Mackintosh M (2004) Hatching failure increases with severity of population bottlenecks in birds. Proceedings of the National Academy of Sciences, USA, 101, 558-561.

Brook BW (2004) Australian bird invasions: accidents of history? Ornithological Science, 3, 
33-42.

Carlson SM, Cunningham CJ, Westley PAH (2014) Evolutionary rescue in a changing world.

Trends in Ecology \& Evolution, 29, 521-530.

Cassey P, Blackburn TM. Duncan RP, Gaston KJ (2005) Causes of exotic bird establishment across oceanic islands. Proceedings of the Royal Society, London, B., 272, 2059-2063.

Cassey P, Blackburn TM, Russell G, Jones KE, Lockwood JL (2004) Influences on the transport and establishment of exotic bird species: an analysis of the parrots (Psittaciformes) of the world. Global Change Biology, 10, 417-426.

Cassey P, Blackburn TM, Sol D, Duncan RP, Lockwood J (2004b) Introduction effort and establishment success in birds. Proceedings of the Royal Society, London, B, 271, S405-S408.

Cassey P, Prowse TAA, Blackburn TM (2014) A population model for predicting the successful establishment of introduced bird species. Oecologia, 175, 417-428.

Caswell H (2001) Matrix Population Models. Sinauer Associates, Inc., Sunderland, Massachusetts.

Caswell H, Lensink R, Neubert MG (2003) Demography and dispersal: life table response experiments for invasion speed. Ecology, 84, 1968-1978.

Caughley G (1994) Directions in conservation biology. Journal of Animal Ecology, 63, 215244.

Chang AL, Grossman JD, Spezio TS, Weskel HW, Blum JC, et al. (2009) Tackling aquatic invasions: risks and opportunities for the aquarium fish industry. Biological Invasions, 11, 773-785.

Chapple DG, Simmonds SM, Wong B (2012) Can behavioral and personality traits influence the success of unintentional species introductions? Trends in Ecology \& Evolution, 27, 57-64.

Colautti RI, Grigorovich IA, Maclsaac HJ (2006) Propagule pressure: a null model for biological invasions. Biological Invasions, 8, 1023-1037.

Crooks JA, Soulé ME (1999) Lag times in population explosions of invasive species: causes and implications. In: Invasive species and biodiversity management (eds Sandlund OT, Schei PJ, Viken A), pp. 103-125. Kluwer Academic Press, Dordrecht, The Netherlands.

Dlugosch KM, Parker IM (2008) Founding events in species invasions: genetic variation, adaptive evolution, and the role of multiple introductions. Molecular Ecology, 17, 431449.

Drake JA, di Castri F, Groves RH, Kruger FJ, Rejmánek M, Williamson M (eds) (1989) Biological Invasions, A Global Perspective. John Wiley \& Sons, Chichester, UK. 
Drake JM, Baggenstos P, Lodge DM (2005) Propagule pressure and persistence in experimental populations. Biology Letters, 1, 480-483.

Duncan RP, Blackburn TM, Veltman CJ (1999) Determinants of geographical range sizes: a test using introduced New Zealand birds. Journal of Animal Ecology, 68, 963-975.

Duncan RP, Bomford M, Forsyth DM, Conibear L (2001) High predictability in introduction outcomes and the geographical range size of introduced Australian birds: a role for climate. Journal of Animal Ecology, 70, 621-632.

Duncan RP, Blackburn TM, Rossinelli S, Bacher S (2014) Quantifying invasion risk: the relationship between establishment probability and founding population size. Methods in Ecology \& Evolution, 5, 1255-1263.

Edmonds CA, Lillie AS, Cavalli-Sforza LL (2003) Mutations arising in the wave front of an expanding population. Proceedings of the National Academy of Sciences, USA, 101, 975-979.

Elton C (1958) The Ecology of Invasions by Animals and Plants. Methuen, London.

Facon B, Hufbauer RA, Tayeh A et al. (2011) Inbreeding depression is purged in the invasive insect Harmonia axyridis. Current Biology, 5, 424-427.

Fauvergue X, Malausa J-C, Giuge L, Courchamp F (2007) Invading parasitoids suffer no Allee effect $\square$ : A manipulative field experiment. Ecology, 88, 2392-2403.

Fenner F (1965) Myxoma virus and Oryctolagus cuniculus: two colonizing species. In: The Genetics of Colonizing Species (eds Baker HG, Stebbins GL), pp. 484-502. Academic Press, New York, NY.

Fox GA (2005) Extinction risk of heterogeneous populations. Ecology, 86, 1191-1198.

Frankham R, Ballou JD, Briscoe DA, Mclnnes KH (2004) A Primer of Conservation Genetics. Cambridge University Press, Cambridge.

Fraser A (1965) Colonization and genetic drift. In: The Genetics of Colonizing Species (eds Baker HG, Stebbins GL), pp. 117-122. Academic Press, New York, NY.

Gaston KJ (1994) Rarity. Chapman \& Hall, London.

Gaston KJ (2003) The Structure and Dynamics of Geographic Ranges. Oxford University Press, Oxford.

Gaston KJ, Blackburn TM (2000) Pattern and Process in Macroecology. Blackwell Science, Oxford.

Gaston KJ, Jones AG, Hanel C, Chown SL (2003) Rates of species introduction to a remote oceanic island. Proceedings of the Royal Society, London, B, 270, 1091-1098.

Gertzen EL, Leung B, Yan ND (2011) Propagule pressure, Allee effects and the probability of establishment of an invasive species (Bythotrephes longimanus). Ecosphere 2(2):artX. doi:10.1890/ES10-000170.1.

Gomulkiewicz R, Holt R (1995) When does Evolution by Natural Selection Prevent Extinction? Evolution, 49, 201-207. 
Gonzalez A, Ronce O, Ferriere R, Hochberg ME (2013) Evolutionary rescue: an emerging focus at the intersection between ecology and evolution. Philosophical transactions of the Royal Society of London. Series B, Biological sciences, 368, 20120404.

Grevstad FS (1999) Factors influencing the chance of population establishment: implications for release strategies in biological control. Ecological Applications, 9, 1439-1447.

Haccou P, Iwasa Y (1996) Establishment probability in fluctuating environments: a branching process model. Theoretical Population Biology, 50, 254-280.

Haccou P, Vatutin V (2003) Establishment success and extinction risk in autocorrelated environments. Theoretical Population Biology, 64, 303-314.

Harper JL (1965) Establishment, aggression and cohabitation in weedy species In: The Genetics of Colonizing Species (eds Baker HG, Stebbins GL), pp. 243-265. Academic Press, New York, NY.

Hayes KR, Barry SC (2008) Are there any consistent predictors of invasion success? Biological Invasions, 10, 483-506.

Holt RD, Barfield M, Gomulkiewicz R (2005) Theories of niche conservatism and evolution: could exotic species be potential tests? In: Species invasions: Insights into ecology, evolution and biogeography. (eds Sax DF, Stachowicz JJ, Gaines SD), pp. 259-290. Sinauer Associates Inc., Sunderland, Massachusetts.

Hopper KR, Roush RT (1993) Mate finding, dispersal, number released, and the success of biological control introductions. Ecological Entomology, 18, 321-331.

Hufbauer RA, Facon B, Ravigné $V$ et al. (2012) Anthropogenically induced adaptation to invade (AIAI): contemporary adaptation to human-altered habitats within the native range can promote invasions. Evolutionary Applications, 5, 89-101.

Hufbauer RA, Rutschmann A, Serrate B, Vermeil de Conchard H, Facon B (2013) Role of propagule pressure in colonization success: disentangling the relative importance of demographic, genetic and habitat effects. Journal of Evolutionary Biology, 26, 16911699.

Hulme P E (2009) Trade, transport and trouble: managing invasive species pathways in an era of globalization. Journal of Applied Ecology, 46, 10-18.

Hulme PE, Bacher S, Kenis M, Klotz S, Kühn I, et al. (2008) Grasping at the routes of biological invasions: a framework for integrating pathways into policy. Journal of Applied Ecology 45:403-414.

Jeschke JM (2008) Across islands and continents, mammals are more successful invaders than birds. Diversity and Distributions, 14, 913-916.

Kolbe JJ, Glor RE, Schettino LR, Lara AC, Larson A, Losos JB (2004) Genetic variation increases during biological invasion by a Cuban lizard. Nature, 431, 177-181.

Lanfear R, Kokko H, Eyre-Walker A (2014) Population size and the rate of evolution. Trends in ecology \& evolution, 29, 33-41. 
Lockwood JL, Cassey P, Blackburn TM (2005) The role of propagule pressure in explaining species invasion. Trends in Ecology and Evolution, 20, 223-228.

Lockwood JL, Cassey P, Blackburn TM (2009) The more you introduce the more you get: the role of colonization and propagule pressure in invasion ecology. Diversity and Distributions, 15, 904-910.

Lockwood JL, Hoopes MF, Marchetti MP (2013) Invasion Ecology, $2^{\text {nd }}$ edition. Blackwell Publishing, Oxford.

McCauley DE (1991) Genetic consequences of local-population extinction and recolonization. Trends in Ecology \& Evolution, 6, 5-8.

Mack RN (2003) Global plant dispersal, naturalization, and invasion: pathways, modes and circumstances. In: Invasive Species: Vectors and Management Strategies. (eds Ruiz GM, Carlton JT), pp. 3-30. Island Press, Washington, DC.

Mayr, E (1965) Summary. In: The Genetics of Colonizing Species (eds Baker HG, Stebbins GL), pp. 553-562. Academic Press, New York, NY.

Memmott J, Craze PG, Harman HM, Syrett P, Fowler SV (2005) The effect of propagule size on the invasion of an alien insect. Journal of Animal Ecology, 74, 50-62.

Merilä J, Bjorklund M, Baker AJ (1996) The successful founder: genetics of introduced Carduelis chloris (greenfinch) populations in New Zealand. Heredity, 77, 410-422.

Morris WF, Doak DF (2002) Quantitative Conservation Biology: The Theory and Practice of Population Viability Analysis. Sinauer Associates Inc., Sunderland, MA.

Nei M, Mauyama T, Chakraborty R (1975) The bottleneck effect and genetic variability in populations. Evolution, 29, 1-10.

Novak SJ, Mack RN (2005) Genetic bottlenecks in alien plant species: influence of mating systems and introduction dynamics. In Species Invasions: Insights into Ecology, Evolution and Biogeography (eds Sax DF, Stachowicz JJ, Gaines SD), pp. 201-228. Sinauer Associates Inc., Sunderland, MA.

Pyšek P, Richardson DM (2008) Traits associated with invasiveness in alien plants: where do we stand? In: Biological Invasions (ed Nentwig W), pp. 97-125. Springer-Verlag, Berlin.

Pyšek P, Sadlo J, Mandak B, Jarošik V (2003) Czech alien flora and the historical pattern of its formation: what came first to Central Europe. Oecologia, 135, 122-130.

Richardson DM, Pyšek P, Carlton J (2011) A compendium of essential concepts and terminology in invasion ecology. In: Fifty Years of Invasion Ecology. The Legacy of Charles Elton (ed Richardson DM), pp. 409-420. John Wiley \& Sons Ltd, Oxford.

Roman J, Darling JA (2007) Paradox lost: genetic diversity and the success of aquatic invasions. Trends in Ecology \& Evolution, 22, 454-464.

Sakai KI (1965) Contributions to the problem of species colonization from the viewpoint of competition and migration. In: The Genetics of Colonizing Species (eds Baker HG, 
Stebbins GL), pp. 215-239. Academic Press, New York, NY.

Sakai AK, Allendorf, FW, Holt JS, Lodge DM, Molofsky J, et al. (2001) The population biology of invasive species. Annual Review of Ecology, Evolution and Systematics, 32, 305-332.

Schiffers K, Bourne EC, Lavergne S, Thuiller W, Travis JMJ (2013) Limited evolutionary rescue of locally adapted populations facing climate change. Philosophical transactions of the Royal Society of London. Series B, Biological sciences, 368, 20120083.

Signorile AL, Wang J, Lutz PWW, Bertolino S, Carbone C, Reuman DC (2014) Do founder size, genetic diversity and structure influence rates of expansion of North American grey squirrels in Europe? Diversity and Distributions, 20, 918-930.

Simberloff D (2009) The role of propagule pressure in biological invasions. Annual Review of Ecology, Evolution and Systematics, 40, 81-102.

Skellam JG (1951) Random dispersal in theoretical populations. Biometrika, 38, 196-218.

Sol D, Maspons J, Vall-Llosera M, Bartomeus GE, García-Peña GE, Piñol J, Freckleton RP (2012) Unravelling the life history of successful invaders. Science, 337, 580-583.

Szucs M, Melbourne BA, Tuff T, Hufbauer RA (2014) The roles of demography and genetics in the early stages of colonization. Proceedings of the Royal Society, London, $B$. 20141073. http://dx.doi.org/10.1098/rspb.2014.1073.

Uller T, Leimu R (2011) Founder events predict changes in genetic diversity during humanmediated range expansions. Global Change Biology, 17, 3478-3485.

Wonham MJ, Walton WC, Ruiz GM, Frese AM, Galil BS (2001) Going to the source: role of the invasion pathway in determining potential invaders. Marine Ecology-Progress Series, 215, 1-12.

Williamson M (1996) Biological Invasions. Chapman \& Hall, London.

Williamson M, Pyšek $P$, Jarošík V, Prach K (2005) On the rates and patterns of spread of alien plants in the Czech Republic, Britain, and Ireland. Ecoscience, 12, 424-433.

Zenni RD, Bailey JK, Simberloff D (2014) Rapid evolution and range expansion of an invasive plant are driven by provenance-environment interactions. Ecology Letters, 17, 727-735. 
Figure 1. Boxplot showing variation in estimates of the global population for wildfowl (Order Anseriformes) species that have or have not ever been introduced to areas beyond the limits of their native geographic range. A binomial general mixed linear model (with a random effect for genus to account for non-randomness due to taxonomy) shows that population sizes are larger for species that have a history of introduction than for those that do not (estimate \pm standard error $=0.64 \pm 0.19, \mathrm{~N}=153, \mathrm{P}<0.001$ ). Data on population size were those used in Blackburn \& Duncan (2001), while a list of introduced wildfowl species came from the Global Avian Invasions Atlas (GAVIA) database (E. Dyer \& T. M. Blackburn, unpublished).

Figure 2. Establishment probability versus introduced population size for 55 of psyllid populations released in New Zealand. Introductions spanned a range of population sizes (10 introductions of 2, 4, 10, 30 and 90 pysillids and 5 introductions of 270 psyllids), and were considered successful if populations were still present after five years. Grey crosses are the raw data showing successful ( $y$-axis values $>1$ ) and unsuccessful $(y$-axis values $<0$ ) establishment as a function of introduced population size, while the filled circles show the proportion of populations that established for each population size. The curved lines show the maximum likelihood fits of different models to the data: dashed line = demographic stochasticity alone; dotted line $=$ demographic stochasticity plus Allee effects; solid line = demographic stochasticity plus among-population heterogeneity. The inset panel shows the distribution of probabilities that each individual leaves a surviving lineage, $p$, for different populations modeling among-population heterogeneity. From Duncan et al. (2014), based on data in Memmott et al. (2005).

Figure 3. Flow chart of the cause-effect sequence of events whereby low propagule pressure results in low genetic variation, slow population growth causing further genetic erosion, and finally a dampened ability to evolve to new conditions in the alien range. Contrast this outcome to the sequence of events expected when propagule pressure is high. Any one of the events in this sequence can add to the likelihood that an initially small founder population will likely go extinct due to genetic issues.

Figure 4. The relationship between the number of birds introduced and relative hatching failure rate (the difference between the failure rate in the alien and native source populations) for alien bird species established in New Zealand. Species introduced in smaller numbers show a larger increase in failure rates in the alien relative to the native population. Species are: 1, Callipepla californica; 2, Turdus merula; 3, Sturnus vulgaris; 4, 
Fringilla coelebs; 5, Carduelis carduelis; 6, Car. flammea; 7, Passer domesticus; 8, Alauda arvensis; 9, T. philomelos; 10, Emberiza citrinella; 11, Prunella modularis; 12, Chloris chloris; 13, Acridotheres tristis; 14, Branta canadensis; and 15, Corvus frugilegus. From Briskie \& Mackintosh (2004).

Figure 5. A visual explanation of the U-shaped genetic diversity pattern shown by Dlugosch \& Parker (2008). Multiple, independently-founded alien populations lose genetic diversity (the down-slope of the $U$ ), but eventually coalesce to form one large, panmictic population, thereby increasing the total genetic diversity (the up-slope of the $U$ ). The depth of the $U$ is dependent on the number of individuals released at each location and the degree to which the transport mechanism 'sampled' individuals representing divergent genetic backgrounds.

Figure 1.

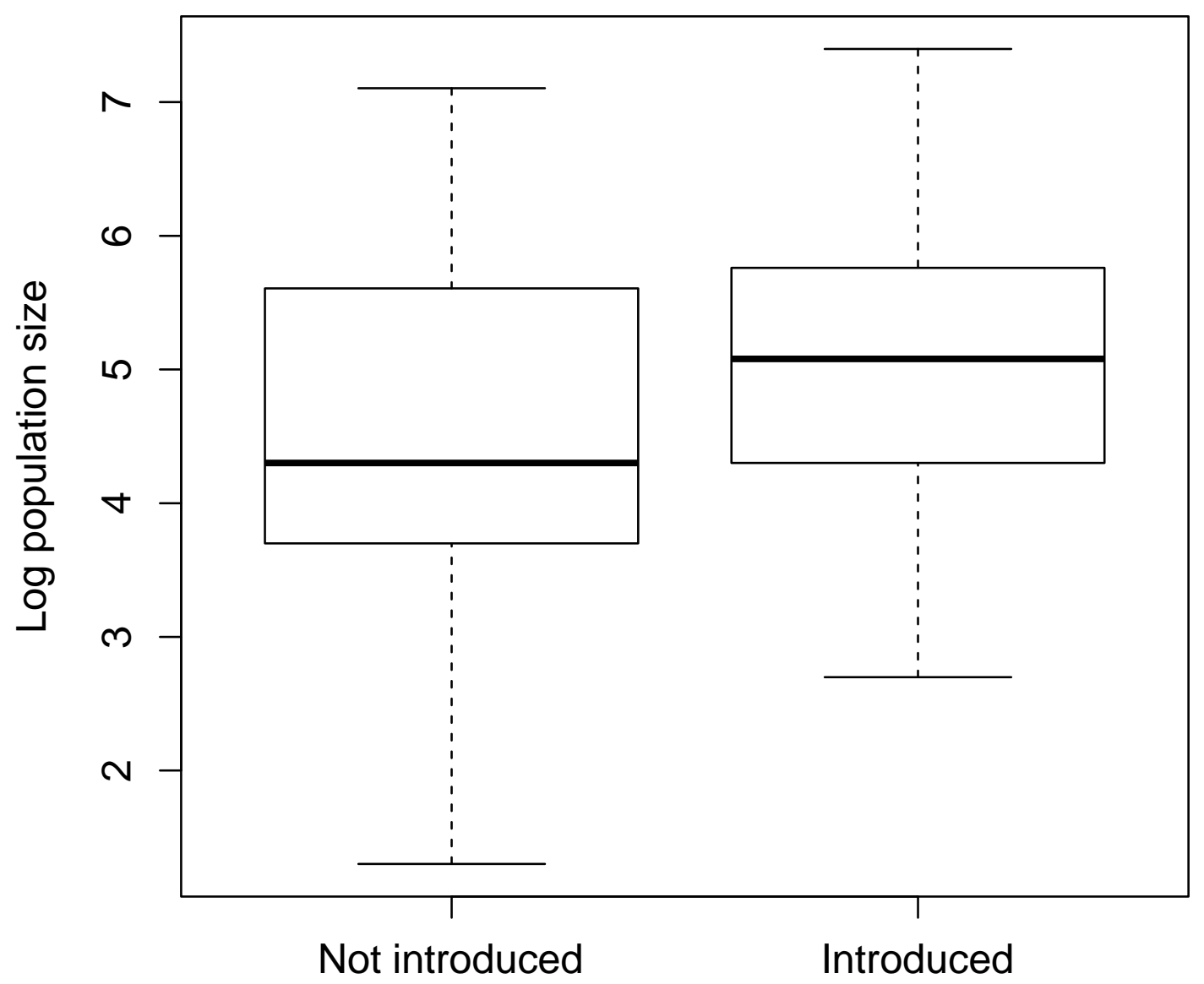


Figure 2.

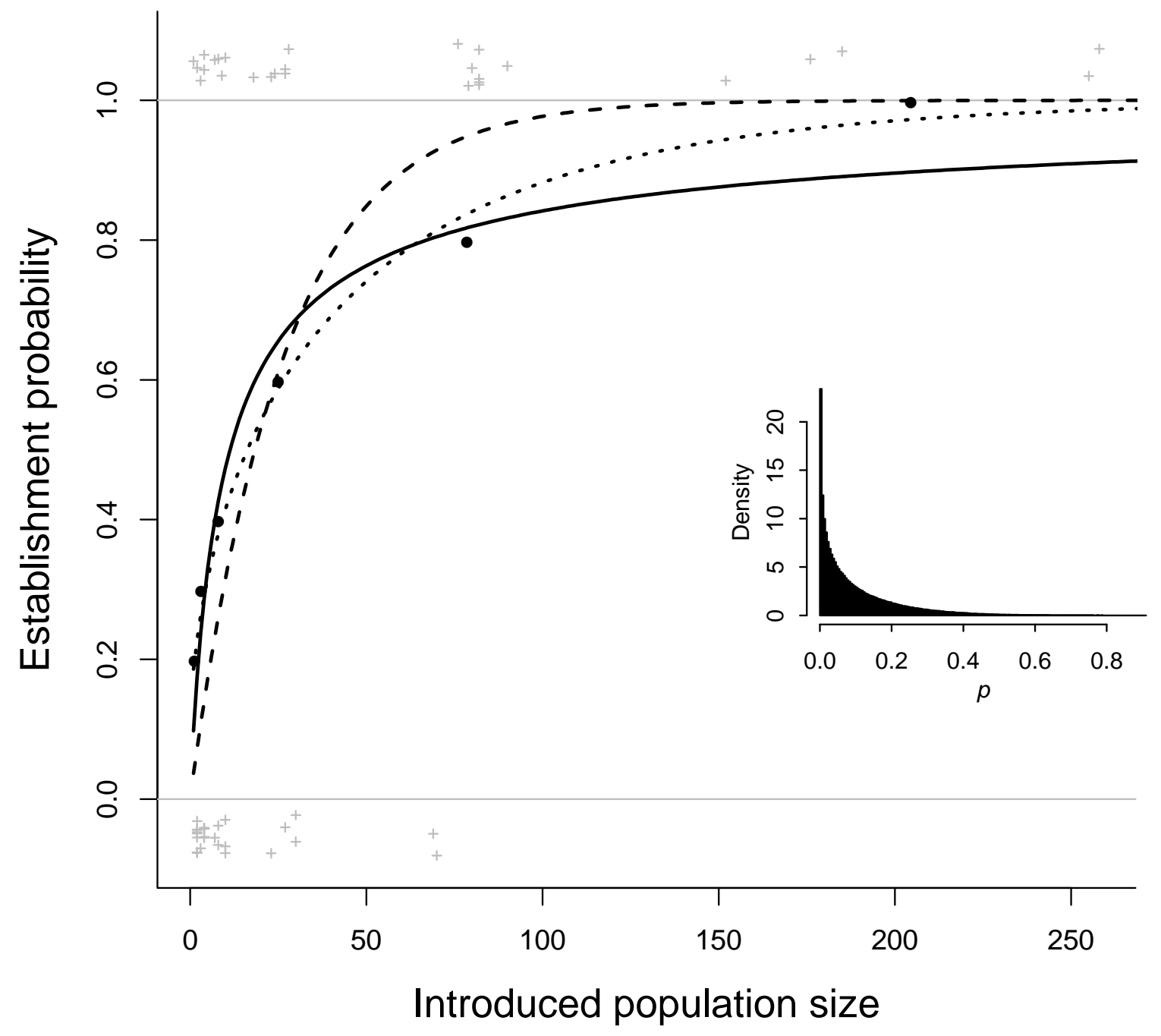


Figure 3.

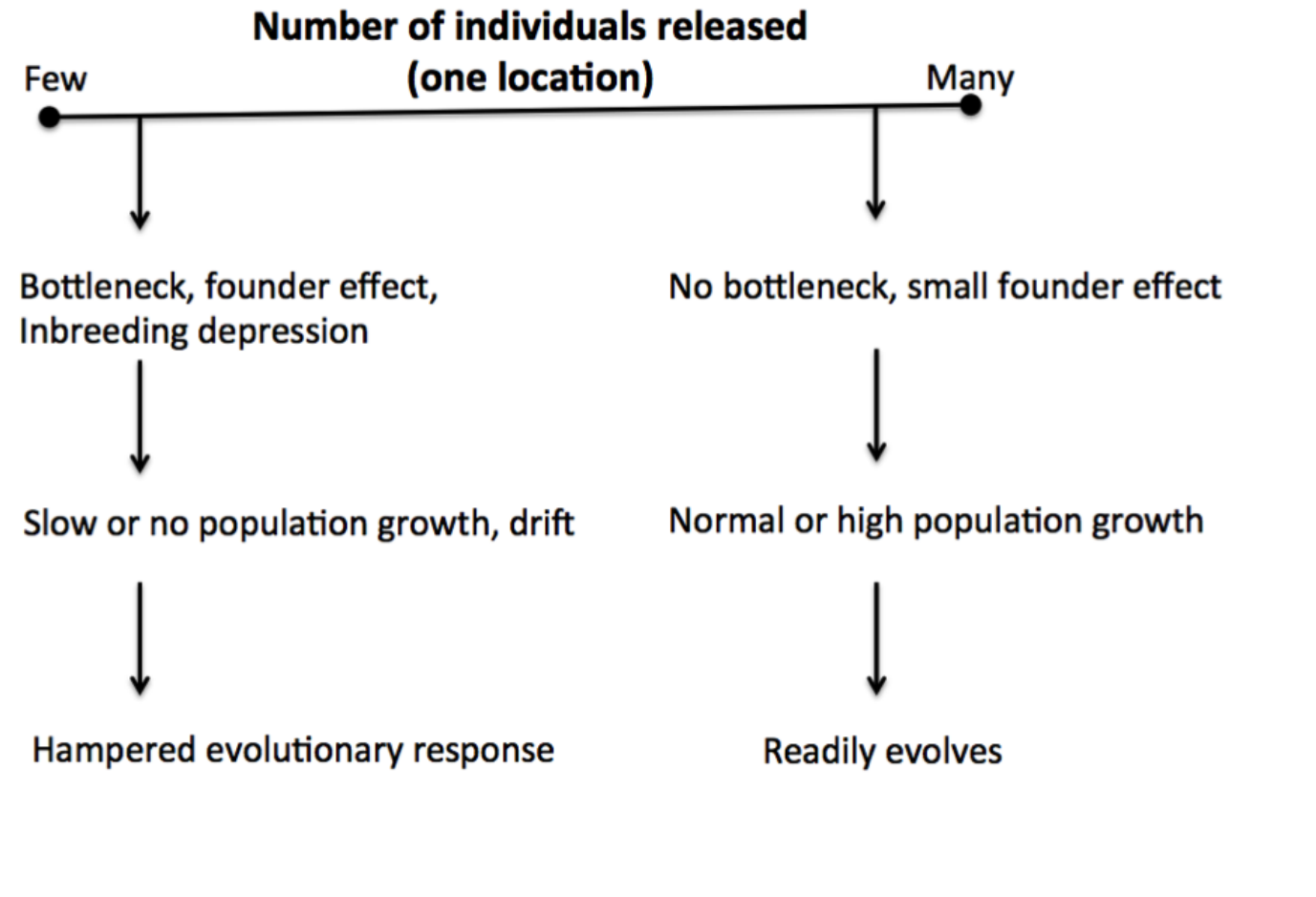


Figure 4.

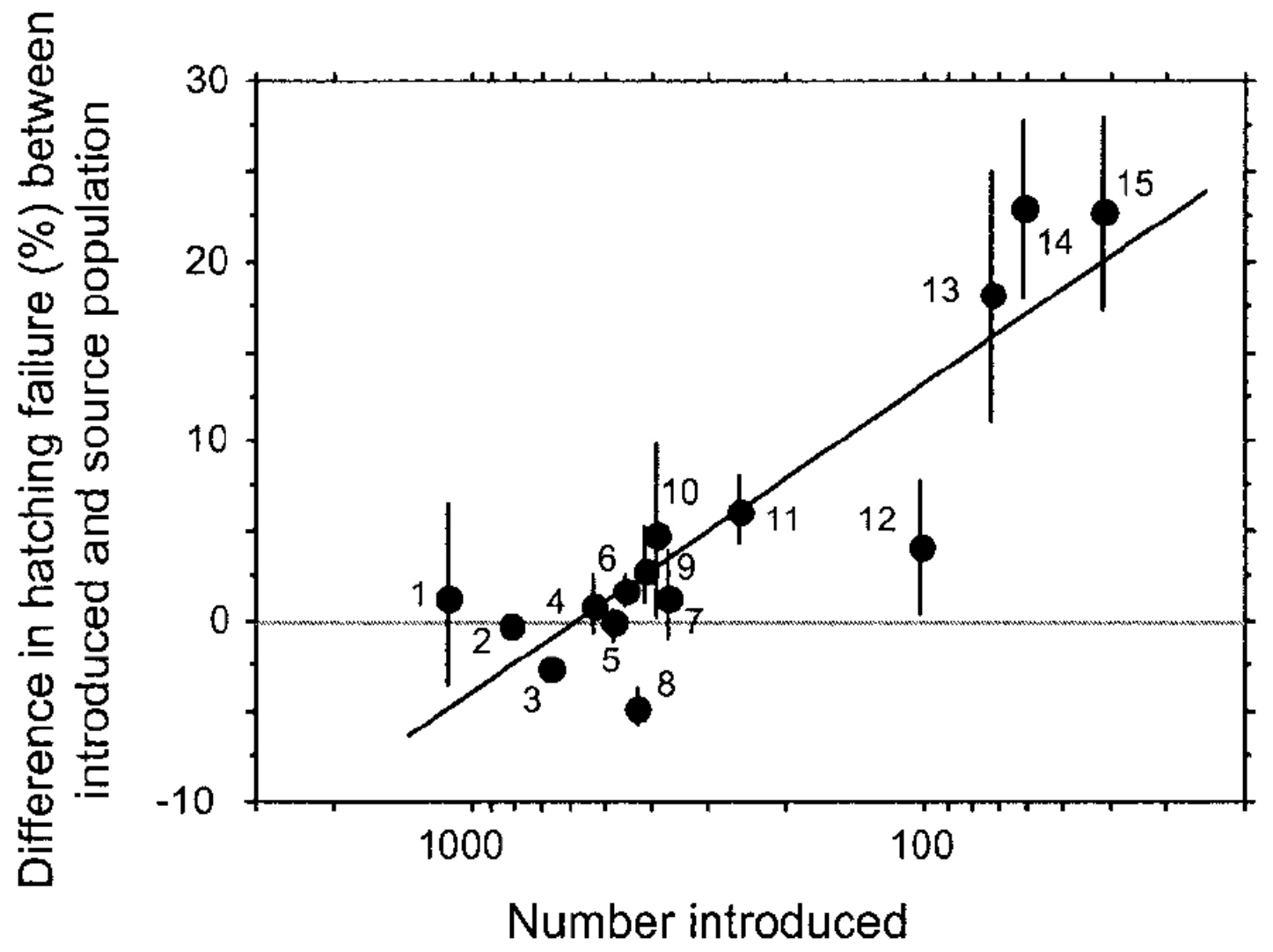


Figure 5.

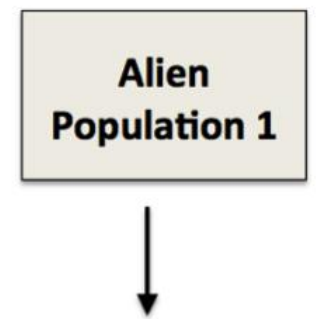

Founder Effect

Drift

Bottleneck

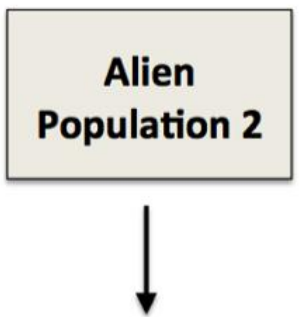

Founder Effect

Drift

Bottleneck

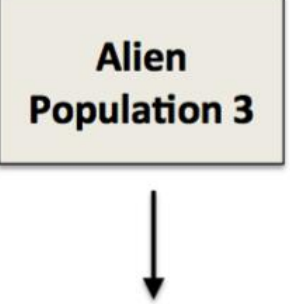

Founder Effect

Drift

Bottleneck

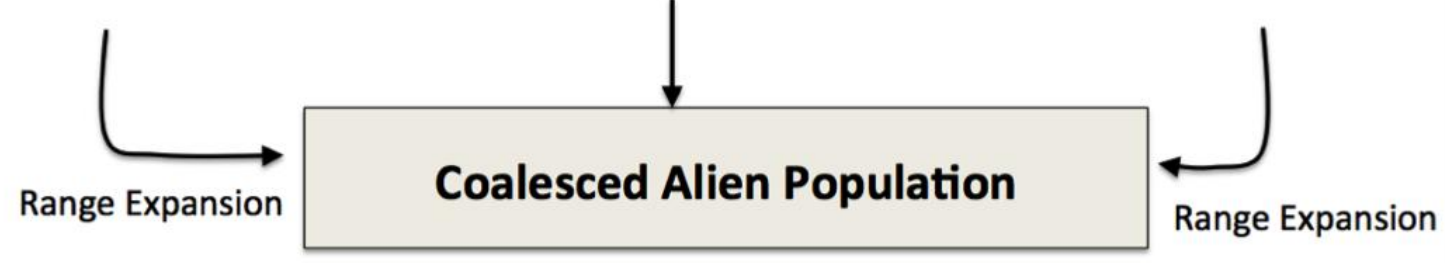

